\title{
Assessing the transferability of statistical predictive models for leaf area index between two airborne discrete return LiDAR sensor designs within multiple intensely managed Loblolly pine forest locations in the south-eastern USA
}

Matthew Sumnall ${ }^{\mathrm{a}}$, Alicia Peduzzi ${ }^{\mathrm{b}}$, Thomas R. Fox ${ }^{\mathrm{a}}$, Randolph H. Wynne ${ }^{\mathrm{c}}$, Valerie A. Thomas ${ }^{\mathrm{d}}$ and Bruce Cook ${ }^{\mathrm{e}}$.

${ }^{a}$ Virginia Polytechnic Institute and State University, Department of Forest Resources and Environmental Conservation, 228 Cheatham Hall (Mail Code: 0324), Blacksburg, VA 24061, USA.

${ }^{\mathrm{b}}$ United States Dept. of Agriculture - Forest Service, 507, 25th Street, Ogden, UT 84401, USA.

c Virginia Polytechnic Institute and State University, Department of Forest Resources and Environmental Conservation, 319 Cheatham Hall (Mail Code: 0324), Blacksburg, VA 24061, USA

d Virginia Polytechnic Institute and State University, Department of Forest Resources and Environmental Conservation, 307A Cheatham Hall (Mail Code: 0324), Blacksburg, VA 24061, USA.

${ }^{\mathrm{E}}$ NASA Goddard Space Flight Center, Biospheric Sciences Laboratory, Code 618, Greenbelt, MD 20771, USA.

Abstract

Leaf area is an important forest structural variable which serves as the primary means of mass and energy exchange within vegetated ecosystems. The objective of the current study was to determine if leaf area index (LAI) could be estimated accurately and consistently in five intensively managed pine plantation forests using two multiple-return airborne LiDAR datasets. Field measurements of LAI were made using the LiCOR LAI2000 and LAI2200 instruments within 116 plots were established of varying size and within a variety of stand conditions (i.e. stand age, nutrient regime and stem density) in North Carolina and Virginia in 2008 and 2013. A number of common LiDAR return height and intensity distribution metrics were calculated (e.g. average return height), in addition to ten indices, with two additional variants, utilized in the

27 surrounding literature which have been used to estimate LAI and fractional cover, were calculated from return heights and intensity, for each plot extent. Each of the indices were assessed for correlation with each other, and were used as independent variables in linear regression analysis with field LAI as the dependent variable. All LiDAR derived metrics were also entered into a forward stepwise linear regression. The results from each of the indices varied

32 from an $\mathrm{R}^{2}$ of 0.33 (S.E. 0.87) to 0.89 (S.E. 0.36). Those indices calculated using ratios of all 
returns produced the strongest correlations, such as the Above and Below Ration Index (ABRI)

34 and Laser Penetration Index 1 (LPI1). The regression model produced from a combination of

35 three metrics did not improve correlations greatly $\left(\mathrm{R}^{2} 0.90\right.$; S.E. 0.35$)$. The results indicate that

36 LAI can be predicted over a range of intensively managed pine plantation forest environments

37 accurately when using different LiDAR sensor designs. Those indices which incorporated counts

38 of specific return numbers (e.g. first returns) or return intensity correlated poorly with field

39 measurements. There were disparities between the number of different types of returns and

40 intensity values when comparing the results from two LiDAR sensors, indicating that predictive

41 models developed using such metrics are not transferable between datasets with different

42 acquisition parameters. Each of the indices were significantly correlated with one another, with

43 one exception (LAI proxy), in particular those indices calculated from all returns, which

44 indicates similarities in information content for those indices. It can then be argued that LiDAR

45 indices have reached a similar stage in development to those calculated from optical-spectral

46 sensors, but which offer a number of advantages, such as the reduction or removal of saturation

47 issues in areas of high biomass.

48

49 Keywords: Loblolly pine; Forest management; LiDAR; Remote sensing; Leaf area index.

50

51 1. Introduction

52 The surface area of the foliated elements within the forest canopy is the primary surface which

53 controls the processes of canopy-gas exchange, such as photosynthesis (Duchemin et al., 2006),

54 evaporation (Cleugh et al., 2007), transpiration (Chen et al., 2005), rainfall interception (Chen et

55 al., 2006), and carbon flux (Leuning et al., 2005). This biophysical parameter is typically 
assessed though leaf area index (LAI), which can be defined as the ratio of half of the total leaf

57 surface area per unit of ground area, and for coniferous species which have cylindrical needles,

58 the projected or hemi-surface area of the needles per unit of ground area (Chen and Black, 1992).

59 As a result LAI varies with hydrological, biochemical, and biophysical processes, either due to natural stand development of forest management practices (e.g. initial site treatment, thinning,

61 fertilization and vegetation control). Given the role of LAI in determining many forest ecosystem

62 processes, several techniques have been developed to rapidly estimate LAI.

64 The most common methods used for estimating LAI across the landscape-scale rely on the 65 empirical relationships between LAI and various manipulations of spectral information from 66 airborne or space-borne imagery. The estimates of LAI from such imagery can be complicated 67 by variation in the properties of the solar radiation reflected from the earth's surface which can 68 be attenuated by atmospheric attributes (e.g. water vapor), and land cover properties (e.g. 69 understory vegetation, senescent leaves, shadows, etc.) which can alter the spectral signature of 70 the surface type (Erikson et al., 2006), in addition to the mixing of signatures (Bioucas-Dias et 71 al., 2012). A drawback of optical imagery is that it is that it is appropriate for examining 72 horizontally distributed features only.

74 More recently, numerous methods have been developed for the analysis of datasets obtained 75 through Light Detection and Ranging (LiDAR) to estimate a suite of forest biophysical 76 characteristics. Airborne small-footprint LiDAR remote sensing, with high point densities, can 77 characterize both horizontal and vertical structures within forested environments. The use of 78 LiDAR has rapidly come into prominence in estimating forest characteristics, such as canopy 
79 height, basal area, timber volume, and biomass (Evans et al., 2009), through the use of

80 regression methods using LiDAR derived metrics related to the return vertical distribution and

81 intensity of LiDAR returns over a range of scales and locations (Anderson et al. 2008; Lefsky et

82 al., 2002; Lim et al., 2003a; Lim et al., 2003b; Maltamo et al., 2005; Næsset, 2002). The

83 derivation of individual tree metrics is possible using small-footprint laser data with a sufficient

84 point density (e.g. Kaartinen et al., 2012).

85

86 There is an increasing body of research attempting to use the three-dimensional structural

87 information from LiDAR to estimate LAI based on statistical methods. Many small footprint

88 LiDAR systems are capable of recording multiple discrete returns per laser pulse (e.g. between

89 one and five returns). Whilst LiDAR derived statistical models have found similar relationships

90 between dependent and independent variables for many examples of forest inventory metrics,

91 each model is calibrated and validated against local field data. Reliable models which can be

92 transferred to other locations are unfortunately lacking. In addition many of the LiDAR derived

93 predictors are often highly correlated, which can bias model estimates (Field, 2013).

94

95 The majority of LAI ground measurements used for validation of remote sensing data is based on

96 indirect optical and non-destructive measurements. Due to the methods in deriving LAI from

97 such techniques, a common variable used is effective LAI, which is related to gap fraction, and

98 differs from 'true' LAI because the leaves or needles are not randomly distributed within the

99 canopy and can be clumped within shoots. Effective LAI also includes the areas of branches and

100 stems (Stenberg, 1996). As in Solberg et al. (2009) According to Beer-Lambert law, the effective 
101 LAI might be derived for a given forest vertical position from the number of LiDAR pulses to

102 pass through that point, and expressed as:

$$
L A I_{e}=\beta \times \ln \left(P^{-1}\right)
$$

103 Where $L A I_{e}$ is the effective LAI, $\beta$ is the slope parameter to be predicted, and $P$ is number of 104 pulses. There are a number of examples of LiDAR derived indices or ratios of first, last and 105 single returns, intended to emulate equation 1, being produced in the related research (e.g. 106 Morsdorf et al., 2006; Korhonen et al., 2011; Solberg et al., 2009; Zhao and Popescu, 2009), 107 and regressing them against effective LAI over a variety of forest types.

A number of challenges related to the differences in LiDAR sensor design and acquisition 110 parameters exist. As pulse penetration properties and return frequency distribution can differ 111 between LiDAR acquisitions (Næsset, 2009; Hopkinson, 2006), the proportions of first-of-many, 112 single and last returns will differ when comparing systems capable of detecting differing types of 113 returns. Another issue prevalent in discrete return LiDAR, is the 'blind spot' following each 114 detected return (up to 1.2-5m), during which nothing can be detected (Reitberger et al., 2008). 115 The usage of LiDAR intensity remains a contested issue due to the proprietary methods that 116 commercial sensors use to report return intensity which can change in flight, making it 117 impossible to directly compare two discrete returns (Lim et al., 2003a). These issues may be 118 symptomatic of locational or data acquisition specific differences pose problems to the 119 transferability of LiDAR based LAI models.

121 A number of studies have attempted to assess multiple LiDAR derived indices or statistical 122 predictive models against one another. One such example is Richardson et al. (2009), where four 
123 previously published LAI predictive models were assessed for prediction accuracy for a number 124 of locations within Washington State, USA. The results varied in terms of $\mathrm{R}^{2}$ values from 0.49 -

1250.66 , which was lower than in the original studies. The differences in estimates were ascribed to 126 differences in vegetation types, LAI ranges and LiDAR acquisition parameters within each of the 127 studies. The research outlined in Hopkinson and Chasmer (2009) assessed four LiDAR derived 128 indices of fractional cover across seven study areas within Canada, with acquisitions from two 129 generations of Optech airborne laser scanning systems. The authors report $\mathrm{R}^{2}$ values for 130 predictions between $0.70-0.78$, with the highest correlations existing for indices produced from 131 the sum of intensity values from both the ground or canopy vertical elements relative to the total 132 for all study sites.

134 The aim of the current study was to test a number approaches for estimating LAI in homogenous 135 coniferous forest with various management treatments and understory vegetation conditions, 136 covering a wide range of LAI values. The specific objectives were to: (1) estimate LAI over 137 multiple locations and sensor designs/acquisition parameters through a number of modeling 138 approaches, and (2) evaluate the modeling approaches for estimating LAI from airborne discrete 139 return LiDAR.

\section{2. Materials and methods}

\section{$142 \quad 2.1$ Study sites}

143 A total of five study sites were visited which are located within North Carolina and Virginia, 144 USA, were used for the current research project. The initial three sites were established in 2008 145 and maintained in support of research studies investigating the role of intensive management in 
146 optimizing Loblolly pine (Pinus taeda L.) production. These studies were a joint effort between

147 the Forest Productivity Cooperative (FPC) (http://forestproductivitycoop.net/), academic

148 institutions, the USDA Forest service, the Virginia Department of Forestry and private industry.

150 The first of these sites was the RW195501 trial (RW19), which is part of a region wide study 151 examining the effects fertilization and thinning in mid-rotation stands. This trial is located in the 152 Piedmont of Virginia in Appomattox County at $37^{\circ} 26^{\prime} 32^{\prime \prime} \mathrm{N}$ and $78^{\circ} 39^{\prime} 43^{\prime \prime} \mathrm{W}$. A total of 32 153 plots were installed in a 13 year old stand. The plots vary in size from approximately 400 to $1541280 \mathrm{~m}^{2}$ and could be of a square or rectangular shape. At the time of the LiDAR acquisition in 155 summer 2008, only plots had been established and no additional silvicultural techniques had 156 been applied besides the traditional forest operational practices used in the area.

158 The second site in Virginia, was the RW180601 (RW18), which was also part of a region wide 159 study designed with the objective of understanding the optimal rates and frequencies of nutrient 160 additions for rapid growth in young stands. The trial was located in the Piedmont site of Virginia, 161 Brunswick County at $36^{\circ} 40^{\prime} 51^{\prime \prime} \mathrm{N}$ and $77^{\circ} 59^{\prime} 13^{\prime \prime} \mathrm{W}$. A total of 40 plots were installed in 1999 162 in a 6 year old planted stand. These plots had complete weed control and five nutrient treatments, 163 as follows: $0,67,134,201$, and $269 \mathrm{~kg} /$ ha nitrogen $(\mathrm{N})$ applied with phosphorous $(0.1 \times \mathrm{N})$.

164 Nutrient application frequencies were at 1,2, 4 and 6 year intervals. Thirty plots were thinned in 165 2008. Plot size varied from approximately 400 to $470 \mathrm{~m}^{2}$, and again could be of a square or 166 rectangular shape. 
168 The third site was the Southeast Tree Research and Education Site (SETRES), and was located in 169 sand hills of North Carolina, in Scotland County, at $34^{\circ} 54^{\prime} 17^{\prime \prime} \mathrm{N}$ and $79^{\circ} 29^{\prime} \mathrm{W}$. This trial was 170 established in 1992 in an 8 year old plantation. The goal of the study was to quantify the effects

171 of nutrient and water availability on above and below ground productivity and growth efficiency 172 in Loblolly pine. Treatments consisted of nutrient additions (nitrogen, phosphorus, potassium, 173 calcium and magnesium), and irrigation. See Albaugh et al. (1998) for a complete description of 174 site and treatment. Plot size was $900 \mathrm{~m}^{2}(30 \times 30 \mathrm{~m}), 4$ blocks and 4 plots per block, for a total of 17516 plots.

176

177 Two final study sites were located in North Carolina, USA, and enumerated in 2013. Both sites 178 are managed in support of research studies for the production of Loblolly pine. The first of the 179 sites was established at Parker Tract (Parker) $\left(35^{\circ} 48^{\prime} \mathrm{N}, 76^{\circ} 40^{\prime} \mathrm{W}\right)$ is managed by the USDA 180 forest service for research on climate response, water availability and ecosystem stress (more 181 information can be found at: http://www.nrs.fs.fed.us/data/lcms/tpt/). Understory vegetation was 182 not managed and was present in high density across the whole site. The site was planted in 1992 183 and thinned in 2009 removing approximately 50 to $60 \%$ of the pine biomass. The total site extent 184 was approximately $1.4 \times 0.9 \mathrm{~km}$. Eight field plots were installed throughout the site with a plot 185 size of $15 \times 15 \mathrm{~m}\left(225 \mathrm{~m}^{2}\right)$.

186

187 The second study site was established at the Loblolly pine plantation areas located in Duke 188 Research Forest (Duke) $\left(35^{\circ} 57^{\prime} \mathrm{N} 79^{\circ} 05^{\prime} \mathrm{W}\right)$ which is managed for research and teaching 189 purposes by Duke University. The Duke Forest site is composed of a mix of coniferous and 190 deciduous stands. The site is managed to provide a diversity of stand types and age-class 
191 distributions over a variety of soils and topographic conditions. Silvicultural practices can 192 include may include prescribed burning, disking, pre-commercial and commercial thinning, 193 various regeneration and harvest systems, planting, herbicide application, and fertilization. The 194 sites visited varied in planting date from 1981 to 2005 , and covered an extent of $3.3 \times 2.0 \mathrm{~km}$ 195 (more information can be found at: http://dukeforest.duke.edu/). The understory in pure stands is

196 often sparse, but in mixed or old stands, it is dominated by native hardwoods. A total of twenty 197 field plots were installed throughout the location with a plot size of $15 \times 15 \mathrm{~m}\left(225 \mathrm{~m}^{2}\right)$.

198

\subsection{Field estimates of Leaf Area Index}

200 LAI data was collected using the LiCOR LAI-2000 Plant Canopy Analyzer on each plot during 201 later summer (September 7-19, 2008) with the exception of the RW19 trial, which was measured 202 in January 2009. Above canopy readings were recorded remotely every 15 seconds by placing 203 the instrument in an open field adjacent to the stand during the same data and time that 204 measurements were taken inside the stand. All within stand measurements were made at a height 205 of $1 \mathrm{~m}$ above ground, and facing upwards regardless of the presence of understory or mid-story 206 vegetation. Due to the instruments design all measurements were recorded under diffuse sky 207 conditions at dawn and dusk periods, to ensure the sensor only recorded indirect light. The above 208 and below canopy instruments always faced north with a $90^{\circ}$ view cap, with the sensor directed 209 upwards. Sampling points were distributed equally along a transect. Two transects were recorded 210 for each plot, one close to the edge of the plot and the other in the middle of the plot, with a total 211 of 14-25 readings being taken based on plot dimensions.

213 As LAI measurements for the RW19 location were measured in January 2009, a regression 214 model was produced to generate approximate summer 2008 values. The model was developed 
215

216

217

218

219

220

221

222

223

224

225

226

227

228

229

230

231

232

233

using effective LAI LiCOR measurements made in summer (August) 2005 and winter (February) 2006 from 17 plots $(100 \times 100 \mathrm{~m})$ established in 7 and 10 year old loblolly pine stands. See Peduzzi et al. (2012a and 2012b) for more information.

The 2013 field plots were visited between the $23^{\text {rd }}$ and $27^{\text {th }}$ of October. Field LAI was assessed using the LiCOR LAI-2200 Plant Canopy Analyzer on each plot. Above and below canopy readings were recorded as stated previously. Measurements were made at $1.25 \mathrm{~m}$ above ground height. Two transects were used, one along the tree row at the center of the plot and the second in the gap between rows. Measurements were taken every systematically along the transect, with 30 readings being taken per plot.

The calculation of effective LAI per plot was produced through the LiCOR FV-2000 or FV-2200 software, for data acquired in 2008-9, and 2013, respectively. Plot-level readings were averaged, where ring number 5 measurements were masked to reduce error introduced by the stem and branches of the coniferous trees. Records with transmittance values $>1$ were skipped in order to avoid bad readings that can alter mean values per plot. The above and below canopy readings were matched by time (Welles and Norman, 1991). Estimates of effective LAI were calculated, with no clumping corrections applied, i.e. assuming a random distribution of the components within the canopy. The LAI values for each site are summarized in Table 1.

Table 1

A summary of the LAI values recorded for the five study sites

\begin{tabular}{|l|c|c|c|c|c|c|}
\hline Study Site & $\begin{array}{l}\text { Number of } \\
\text { field plots }\end{array}$ & $\begin{array}{l}\text { LAI } \\
\text { measurement } \\
\text { height (m) }\end{array}$ & LAI mean & $\begin{array}{l}\text { LAI } \\
\text { standard } \\
\text { deviation }\end{array}$ & $\begin{array}{l}\text { LAI } \\
\text { minimum }\end{array}$ & $\begin{array}{l}\text { LAI } \\
\text { maximum }\end{array}$ \\
\hline $\begin{array}{l}R W 18 \\
(2008)\end{array}$ & 40 & 1.0 & 1.56 & 1.30 & 0.45 & 4.85 \\
\hline $\begin{array}{l}R W 19 \\
(2008)\end{array}$ & 32 & 1.0 & 2.56 & 0.27 & 1.93 & 3.05 \\
\hline SETRES & 16 & 1.0 & 2.52 & 0.47 & 1.55 & 3.27 \\
\hline
\end{tabular}




\begin{tabular}{|l|c|c|c|c|c|c|}
\hline$(2008)$ & & & & & & \\
\hline $\begin{array}{l}\text { Duke } \\
(2013)\end{array}$ & 20 & 1.25 & 3.88 & 1.09 & 2.24 & 5.39 \\
\hline $\begin{array}{l}\text { Parker Tract } \\
(2013)\end{array}$ & 8 & 1.25 & 3.20 & 0.63 & 2.24 & 4.11 \\
\hline
\end{tabular}

\subsection{LiDAR data}

238 Small footprint discrete-return LiDAR was acquired for each of the three study areas in 2008.

239 The systems was an Optech ALTM 3100. The system could record multiple returns (1-4) with a 240 sampling density of 5 pulses per meter square. The flying altitude was approximately $1200 \mathrm{~m}$ 241 with a pulse repetition frequency of $70 \mathrm{kHz}$. The laser operated at $1064 \mathrm{~nm}$ with a beam 242 divergence of approximately $0.3 \mathrm{mrad}$. The scan angle was less than $15^{\circ}$. Instrument vertical 243 accuracy over bare ground was $15 \mathrm{~cm}$ and horizontal accuracy is $0.5 \mathrm{~m}$. The LiDAR return 244 intensity was not calibrated and was recorded as integer values between 0 and 255 .

246 Small-footprint discrete-return LiDAR data were acquired for both 2013 study sites coincident 247 with field data capture. The data was provided by the NASA G-LiHT team (further information 248 can be found in Cook et al. (2013)). The scanning LiDAR system was a Riegl VQ-480. The 249 flying altitude was approximately $610 \mathrm{~m}$ with a pulse repetition frequency of $150 \mathrm{kHz}$, recording 250 up to 6 returns per pulse. The approximate pulse density was 6 per meter-square. The laser 251 operated at $1550 \mathrm{~nm}$ with a beam divergence of $0.3 \mathrm{mrad}$. The scan angle was less than $10^{\circ}$. The 252 instruments accuracy over bare ground was $0.25 \mathrm{~cm}$. The LiDAR return intensity was not 253 calibrated and was recorded as an integer value between 0 and 65535.

255 Preprocessing steps were required before metrics could be derived from the LiDAR data for 256 analysis. Each of these steps were performed using the RSC Lastools software (Armston, 2014). 
257 Ground elevation returns were classified through a progressive morphological filter as outlined

258 in Zhang et al. (2003). LiDAR return above ground heights were calculated by subtracting the 259 corresponding ground point heights, interpolated into a surface (nearest neighbor method), from 260 the original (unclassified) dataset.

262 All LiDAR returns which intersected within field plot horizontal extents were clipped from the 263 datasets, and metrics generated utilizing the R statistical software (version 3.1.1.) (http://www.r264 project.org/). A suite of LiDAR metrics were calculated based on the distribution of all points 265 and vegetation points (i.e. $>0.2 \mathrm{~m}$ ). Ground points were defined as those return $\underline{\underline{5}} 0.2 \mathrm{~m}$ above 266 ground height. The following metrics were generated for both all and canopy returns: the mean, 267 median, standard deviation, variance, coefficient of variation, skewness and kurtosis (as in: 268 Falkowski et al. 2009; Hudak et al. 2008). Percentiles were calculated for all returns at 5\% 269 increments $(5,10 \ldots 90,95 \%)$ for the proportion of returns. Metrics related to LiDAR return 270 intensity were computed from a single flight line for each plot. The flight line providing the 271 largest number of returns incident within the plot extent was selected and metrics were calculated 272 for the coefficient of variation, skewness and kurtosis for all returns and canopy returns. Canopy 273 density slices, using a modified approach outlined in Peduzzi et al. (2012b), were also computed.

274 These metrics were computed above and below the mode of vegetation returns. Ten $1 \mathrm{~m}$ sections 275 were ( 5 above and 5 below the mode based upon the maximum value of a histogram of the 276 number of returns against height) were classified and metrics generated from the slices 277 corresponding to the proportion of total returns, average height of returns, standard deviation, 278 variance, coefficient of variation, skewness and kurtosis. All of these metrics are summarized in 279 Table 2.

Table 2 
A summary of LiDAR point cloud return height and intensity distribution metrics for each plot level area.

\section{2}

\begin{tabular}{|c|c|}
\hline LiDAR metrics & Symbols \\
\hline All returns & 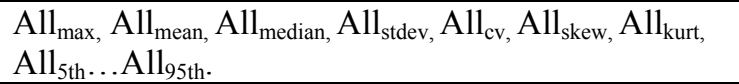 \\
\hline Vegetation returns & 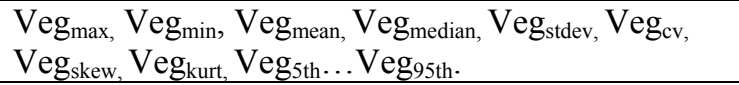 \\
\hline Number of laser pulses & $\operatorname{Grd}_{\text {pulses }}, \operatorname{Veg}_{\text {pulses }}$, All $_{\text {pulses }}$. \\
\hline Proportion of returns & $\begin{array}{l}\mathrm{R}_{i}=\text { total number of } i \text { returns } / \mathrm{R}_{\text {All }} \\
i=\text { first, last, single and intermediate returns }\end{array}$ \\
\hline $\begin{array}{l}\text { Crown density slices around mode of vegetation } \\
\text { returns }\end{array}$ & $\begin{array}{l}\mathrm{CDi}, \mathrm{CDi}_{\text {mean }}, \mathrm{CDi}_{\text {stev }}, \mathrm{CDi}_{\mathrm{CV}}, \mathrm{CDi}_{\text {skew }}, \mathrm{CDi}_{\text {kurt }} \\
\mathrm{CDi}=[\text { number of returns in } i \text { divided by all returns }] \\
(i=+1,+2,+3,+4,+5,0,-1,-2,-3,-4,-5) \\
i=+1 \ldots+5 \text { at } i \text { meters above vegetation mode } \\
i=\text { mode of vegetation returns } \\
i=-1 \ldots-5 \text { at } i \text { meters below vegetation mode }\end{array}$ \\
\hline Intensity value summary from all returns & I.ALL $_{\mathrm{CV}}, \mathrm{I}_{\mathrm{ALL}} \mathrm{AL}_{\text {skew }}, \mathrm{I} \mathrm{ALL} \mathrm{L}_{\text {kurt }}$ \\
\hline Intensity value summary from vegetation returns & I.Veg $_{\mathrm{CV}}, \mathrm{I} \mathrm{Veg}_{\text {skew }}, \mathrm{I} . \mathrm{Veg}_{\text {kurt }}$ \\
\hline
\end{tabular}

283 area index.

In addition to these point cloud summary statistics, other related research studies have examined the use of LiDAR for obtaining estimates of LAI or fractional cover by directly inferring it from a pulse return ratio or the number of canopy-to-total returns (e.g. Barilotti et al., 2006; Hopkinson and Chasmer, 2009; Morsdorf et al., 2006; Solberg et al., 2009). These indices can be related to the principles used by field instruments to indirectly measure LAI on the ground (measuring the solar light transmission or reflectance through the vegetation). The main difference between the canopy interaction of solar and airborne LiDAR laser pulse radiation is geometric. Solar radiation can be incident across a wide range of zenith angles if its temporal and latitudinal distribution is considered, while LiDAR pulses are typically incident at near overhead $\left(0-30^{\circ}\right)$ angles. Any direct LiDAR sampling will be biased towards overhead for a path length close to the height of the canopy, which implies LiDAR estimates maybe directly related to leaf

Each of these indices are based on the frequency or cumulative return intensity of contact of laser pulse returns from within the forest vegetation. These indices use a vertical stratification to 
define 'ground' and producing a ratio of returns form the remaining or complete vertical profile or a ratio of different return types or sum of intensity. The ground return threshold was set to the same as the height which LAI measurements were taken in the field, i.e. $1.0 \mathrm{~m}$ above ground for 2008 data and $1.25 \mathrm{~m}$ for 2013 , as the measurement height was found to be of importance in Sumnall et al. (in press). As before, indices calculated from LiDAR intensity were derived from a single flight line (i.e. the flight line providing the largest number of returns incident within the plot extent). Intensity inputs for these indices correspond to the sum of intensity values from all returns. A summary of each of the indices is provided in Table 3. Two additional indices were constructed, the first was based upon the Above Below Ratio Index (ABRI) which used the cumulative intensity of returns above and below the 'ground' return threshold (ABRI $\left.{ }_{\text {int }}\right)$. And the second is a modification of the Light Penetration Index presented in (Barilotti et al., 2005), which uses the sum of intensity of returns below the ground return threshold divided by the sum of intensity from all returns. This index is referred to as LPI $3_{\text {int.all }}$.

\section{Table 3}

Computation of LiDAR indices. Where $\mathrm{R}_{\text {grd }}$ is the number of returns below the ground threshold (e.g. $\left.1 \mathrm{~m}\right) . \mathrm{R}_{\text {veg }}$ is the number of return above the 'ground' threshold. $R_{\text {All }}$ is the total number of returns. Where $R \cdots$ first is the number of first of many returns (e.g $R_{\text {grd.first }}$ is the sum of ground first returns), $R \ldots$ last is the number of last returns, $R \ldots$ single is the number of single returns, and R...pulses is the total number of number of pulses. Int denotes the sum of return intensities from LiDAR returns, e.g. Int all is the sum of intensity of all returns, Int ${ }_{\text {grd }}$ is the sum of intensity for returns below the ground threshold, whereas Int $\mathrm{veg}_{\mathrm{v}}$ is the sum of intensity. Int...inter is the sum of intensity from intermediate returns (i.e. between first and last).

\begin{tabular}{|c|c|c|c|}
\hline Index & LAI range & Forest types & Calculation \\
\hline $\begin{array}{l}\text { LAI proxy } \\
\text { (LAI PROXY) } \\
\text { (Morsdorf et al, } \\
2006 \text { ) }\end{array}$ & $0.1-1.9$ & $\begin{array}{l}\text { Mountiain } \\
\text { pine (Pinus } \\
\text { mugo subsp. } \\
\text { uncinata) and } \\
\text { stone pine } \\
\text { (Pinus cembra) }\end{array}$ & $L A I_{\text {proxy }}=\frac{R_{\text {Veg.First }}}{R_{\text {Veg.last }}+R_{\text {Veg.single }}}$ \\
\hline $\begin{array}{l}\text { Laser penetration } \\
\text { index } 1 \text { (LPII) } \\
\text { (Barilotti et al, } \\
2005 \text { as cited in } \\
\text { Peduzzi et al., } \\
\text { 2012b) }\end{array}$ & $0.79-4.47$ & Loblolly pine & $L P I 1=\frac{R_{\text {grd }}}{R_{\text {all }}}$ \\
\hline $\begin{array}{l}\text { Laser penetration } \\
\text { Index } 2 \text { (LPI2) } \\
\text { (Solberg et al., }\end{array}$ & $0.58-5.13$ & $\begin{array}{l}\text { Norway spruce } \\
\text { (Picea abies) }\end{array}$ & $L P I 2=\frac{R_{\text {grd.single }}+0.5\left(R_{\text {grd.first }}+R_{\text {grd.last }}\right)}{R_{\text {grd }}+0.5\left(R_{\text {first }}+R_{\text {last }}\right)}$ \\
\hline
\end{tabular}




\begin{tabular}{|c|c|c|c|}
\hline 2009) & & & \\
\hline $\begin{array}{l}\text { First echo Cover } \\
\text { Index }(F C I) \text { and } \\
\text { Last echo Cover } \\
\text { Index }(L C I) \\
\text { (Korhonen } \text { et al., } \\
\text { 2011) }\end{array}$ & $0.15-4.61$ & $\begin{array}{l}\text { Norway spruce } \\
\text { and Scots pine } \\
\text { (Pinus } \\
\text { sylvestris) }\end{array}$ & $\begin{array}{c}F C I=\frac{R_{\text {veg.single }}+R_{\text {veg.first }}}{R_{\text {All.single }}+R_{\text {All.first }}} \\
L C I=\frac{R_{\text {veg.single }}+R_{\text {veg.last }}}{R_{\text {All.single }}+R_{\text {All.last }}}\end{array}$ \\
\hline $\begin{array}{l}\text { Above and } \\
\text { Below Ratio } \\
\text { Index }(A B R I) \\
\text { (Sumnall et al., } \\
\text { in press) }\end{array}$ & $1.39-5.42$ & Loblolly pine & $A B R I=\frac{R_{\text {veg }}}{R_{\text {grd }}}$ \\
\hline $\begin{array}{l}\text { Fractional cover } \\
\text { (multiple) } \\
\text { (Hopkinson and } \\
\text { Chasmer, 2009) }\end{array}$ & $0.18-4.2$ & $\begin{array}{l}\text { Thirteen } \\
\text { coniferous and } \\
\text { deciduous } \\
\text { species. }\end{array}$ & 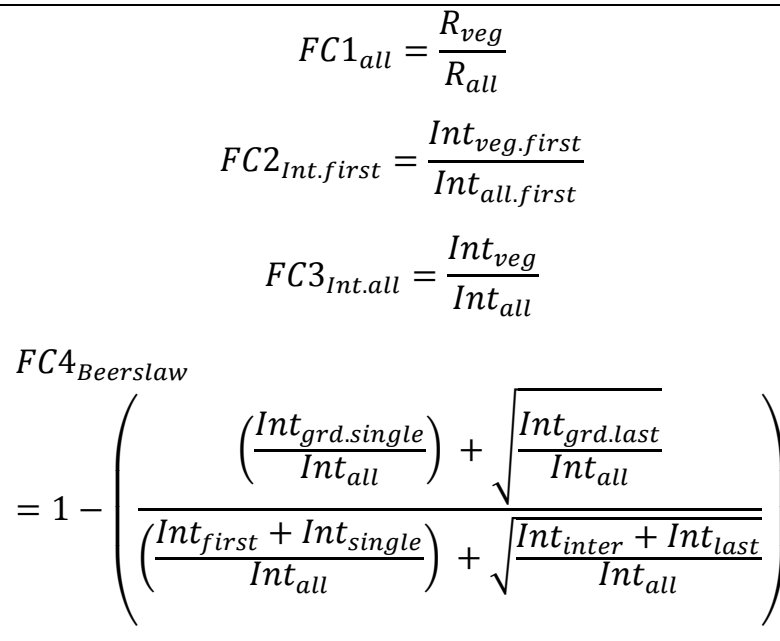 \\
\hline \multicolumn{3}{|c|}{$\begin{array}{l}\text { ABRI changed to use the sum of return intensity } \\
\left(A B R I_{\text {int }}\right) \text {. }\end{array}$} & $A B R I_{\text {Int }}=\frac{\operatorname{Int} t_{\text {veg }}}{\operatorname{Int} t_{\text {grd }}}$ \\
\hline \multicolumn{3}{|c|}{$\begin{array}{l}\text { A modified Light Penetration Index }\left(L P I 3_{\text {int.all }}\right) \text { to } \\
\text { use the sum of return intensity from below } \\
\text { ground threshold. }\end{array}$} & $L P I 3_{\text {Int.all }}=\frac{\operatorname{Int} t_{\text {grd }}}{\operatorname{Int} t_{\text {all }}}$ \\
\hline
\end{tabular}

\subsection{Statistical analysis}

321 A dataset of combining all 116 field plot LiDAR summary metrics were computed and combined

322 with field based LAI measurements. Statistical analyses were conducted in R. Each of the

323 thirteen indices were tested in bivariate regression against field estimates of LAI in order to 324 assess the predictive power of each. Multiple stepwise regression analysis was performed 325 between the field measurements of effective LAI and all of the LiDAR derived indices and those 

unknown, therefore two-tailed significance tests were applied. satisfying individual covariate criteria, was preserved as the final model.

metrics summarized in Table 2. This was to determine if supplementary data could improve the univariate LAI estimation models, or provide a better correlation using different metrics.

Several criteria were used to examine potential models including $\mathrm{R}^{2}$ and adjusted $\mathrm{R}^{2}$. Once a potential model was produced a more rigorous assessment was applied, that included individual covariate significance (Type III error $t$ tests, $\mathrm{p} \leq 0.05$ ); absence of multicolinearity (i.e. variance inflation factor $\leq 1$, Bowerman and O'Connell, 1990) and residual homoscedasticity. Each of the model covariates were examined for contribution to $\mathrm{R}^{2}$ value, significance, individual standard error and variance inflation factor values, and removed as necessary and the stepwise procedure re-implemented. Model validity in multiple linear regression relies partly on the number of observation and covariates. Adjusted $\mathrm{R}^{2}$ is more conservative that $\mathrm{R}^{2}$, thus models where the two were showed little change were sought. Those models which exhibited a combination of the lowest changes of $\mathrm{R}^{2}$ to adjusted $\mathrm{R}^{2}$ and lowest overall dataset standard error, whilst still

A bivariate correlation matrix was produced in order to determine which of the indices, listed in table 3, are linearly related to each other. Pearson correlation coefficients were produced for each of the bivariate comparisons. A specific directional relationship between the variables is

\section{Results}


The best fit regression results comparing the rings 1-4 LAI 2000/2200 measurements for each of

349 the field plot locations are summarized in Table 4, which summarizes $\mathrm{R}^{2}$, standard error and regression equation constant and coefficient values. Four of the regression analyses were found to contain non-linear relationships. Thus, a quadratic transform was applied to $F C 1_{\text {all }}$, square root transforms were applied to the $L P I 1$ and $L P I 2$ and a $\log _{10}$ transform to $A B R I$ variables.

Table 4

Regression statistics for each of the LiDAR derived indices tested. Note that the '*' denotes the students t test result was significant (i.e. $p<0.05$ ).

\begin{tabular}{|c|c|c|c|c|c|}
\hline Model & $\begin{array}{l}\text { Non-linear } \\
\text { transform } \\
(\mathbf{y} / \mathbf{n})\end{array}$ & $\mathbf{R}^{2}$ & Standard Error & Constant & Coefficient \\
\hline \multicolumn{6}{|c|}{ LiDAR return frequency: } \\
\hline$\overline{L A I_{P R O X Y}}$ & $\mathrm{n}$ & 0.066 & 1.033 & $3.384 *$ & -1.803 \\
\hline $\operatorname{sqrt}(L P I 1)$ & $\mathrm{y}$ & 0.885 & 0.362 & $8.159 *$ & -9.276 \\
\hline $\operatorname{sqrt}(L P I 2)$ & $\mathrm{y}$ & 0.858 & 0.403 & $7.084 *$ & $\begin{array}{l}-7.789 \\
\end{array}$ \\
\hline$F C I$ & $\mathrm{n}$ & 0.432 & 0.805 & $-1.049 *$ & 4.388 \\
\hline$L C I$ & $\mathrm{n}$ & 0.811 & 0.464 & 0.146 & 5.258 \\
\hline $\log _{10}(A B R I)$ & $\mathrm{y}$ & 0.886 & 0.360 & $1.641 *$ & 3.861 \\
\hline$\left(F C 1_{\text {all }}\right)^{2}$ & $\mathrm{y}$ & 0.882 & 0.367 & -0.029 & 6.374 \\
\hline \multicolumn{6}{|c|}{ LiDAR intensity: } \\
\hline$\overline{F C 2_{\text {int.first }}}$ & $\mathrm{n}$ & 0.331 & 0.874 & $0.655 *$ & 2.882 \\
\hline$F C 3_{\text {int.all }}$ & $\mathrm{n}$ & 0.447 & 0.795 & 0.234 & 4.372 \\
\hline$F C 4_{\text {beerslaw }}$ & $\mathrm{n}$ & 0.475 & 0.774 & 0.127 & 5.656 \\
\hline$A B R I_{\text {int }}$ & $\mathrm{n}$ & 0.435 & 0.803 & $1.416 *$ & 0.810 \\
\hline$L P I 3_{\text {int.all }}$ & $\mathrm{n}$ & 0.449 & 0.793 & $0.587 *$ & 6.041 \\
\hline
\end{tabular}

In terms of the index metrics generated from the sum of LiDAR return numbers, five of eight models produced high $\mathrm{R}^{2}$ values $(>0.75)$. The regression analysis applied to the $L A I_{P R O X Y}$ calculation produced very low $\mathrm{R}^{2}$ values (i.e. $<0.1$ ) indicating there is very little if any correlation between the index and LAI within this context. The FCI model produced a relatively

361 low $\mathrm{R}^{2}$ value of 0.432 and RMSE of 0.796 , nearly double that of the five remaining models.

362 These five models produced similar $\mathrm{R}^{2}$ and standard error values overall, and were all significant $363(\mathrm{p}<0.05)$, which the exception of the $F C I 1_{\text {all }}$ constant (or intercept) term within the regression model was not significant when assessed with the student's t test (i.e. $p>0.05$ ). 

returns is presented in Figure 1, excluding $L A I_{P R O X Y}$. The graphs for $\operatorname{sqrt}(L P I 1)$ and $\operatorname{sqrt}(L P I 2)$ both depict a linear trend well. It should be noted, however, that LAI values at the upper extents of the LAI range, (approximately $>4$ ) are underestimated for LPI2. The values for the FCI poorly estimates LAI values beyond the average 2-3 LAI value. It is possible to observe a number of groupings within the graph which correspond to the records from individual study sites, for 372 example records for the RW19 and SETRES study sites appear separate from the rest. Elements 373 of which also appear to link with those from Duke and Parker Tract, which may indicate other 374 potential populations. The graph for the LCI predictions depict an overall linear trend, and as 375 before poorly represent LAI estimates at the minimum and maximum of the range. It should also 376 be noted, however, that there is also a relative increase in values for records derived from 2013 377 data (Duke and Parker) in comparison to those from 2008. The remaining two indices $378 \log _{10}(A B R I)$ produced a linear trend well and produced the lowest standard error value (slightly 379 lower than $\operatorname{sqrt}(L P I 1))$. The $F C 1_{\text {all }}^{2}$ model, when compared to those derived from the LPI1 and ABRI does not predict LAI values at the extents of the LAI range encountered here, i.e. where LAI is $<1$ and $>5$.

382 The regression models calculated from the sum of return intensity values were all poor when 383 compared to those described above $\left(\mathrm{R}^{2}<0.5\right)$ with higher RMSE values. For both $F C 3_{\text {int.all }}$ and $384 F C 4_{\text {beerslaw }}$ the constant (or intercept) terms within the regression model were not significant 385 when assessed with the student's t test (i.e. $p>0.05$ ). The graphical representations of these 386 models is presented in Figure 2. LAI values which occupy the extremities on the range of 0-6 are 387 not well predicted in all cases. The predictions presented in Figure 2 show similar distributions to 388 that of the FCI in Figure 1, where the RW19 and SETRES datasets collected in 2008 are separate 
389 from the other records. The records presented for $A B R I_{\text {int }}$ may indicate two separate non-linear 390 distributions.

391 

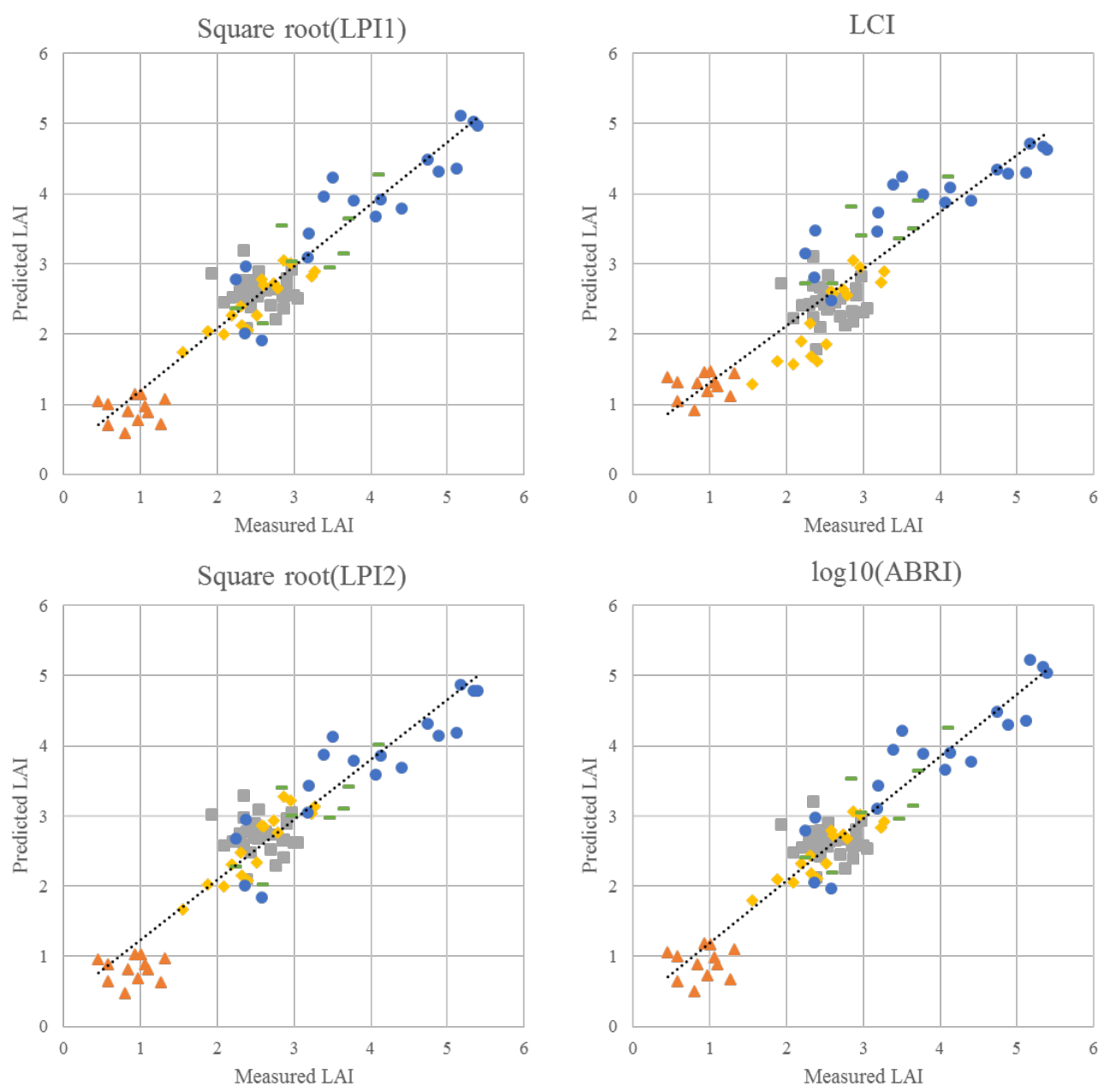

$\Delta$ RW18

RW19

$\checkmark$ SETRES

- Duke

- Parker

FCI
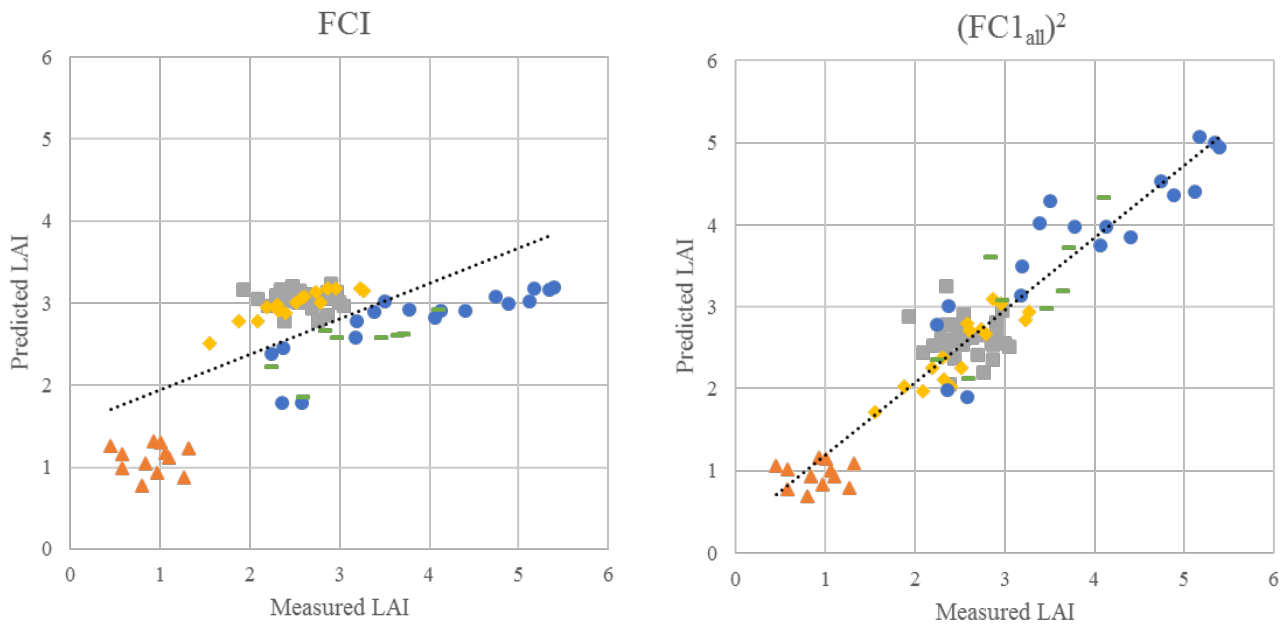

Fig.1. LiDAR return frequency based indices predicted LAI vs. field measured LAI. Color codes represent the observations from each of the five study sites. 

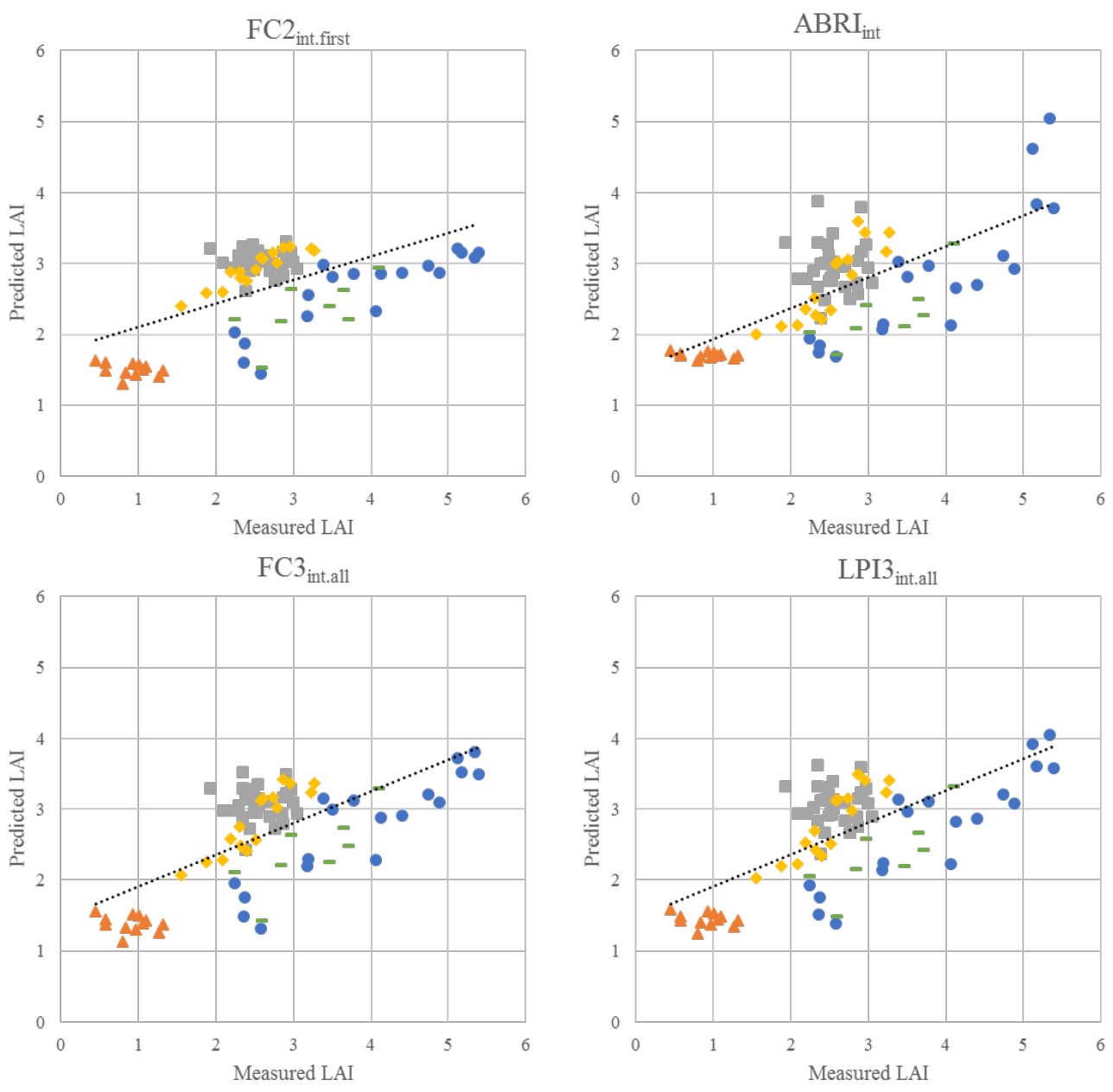

$\triangle$ RW18

RW19

$\checkmark$ SETRES

- Duke

- Parker

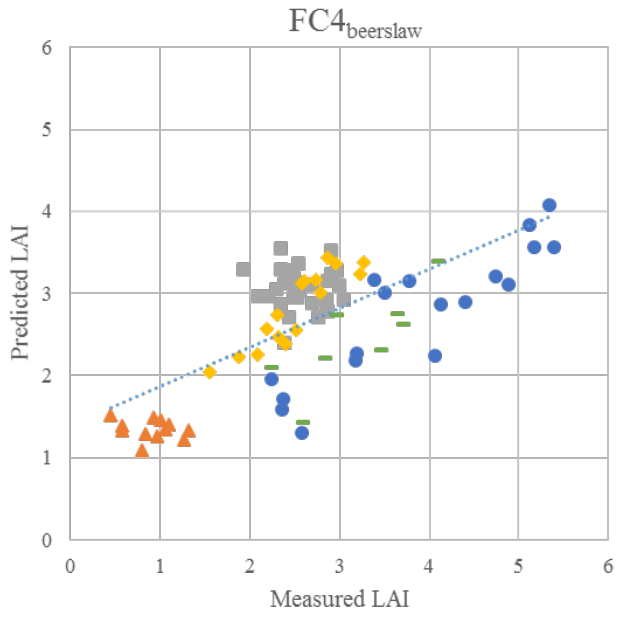

Fig.2. LiDAR return intensity sum based indices predicted LAI vs. field measured LAI. Color codes represent the observations from each of the five study sites. 


\subsection{Consideration of plot area}

403 Plot size varied a great deal between the five study sites, it was therefore necessary to explore

404 how this effected the modeled values of LAI. The LAI estimates were organized by field plot

405 area, and separated into similar groups, these were: (i) $225 \mathrm{~m}^{2}(n=28)$ and $300-399 \mathrm{~m}^{2}(n=3)$; (ii)

406 $400-499 \mathrm{~m}^{2}(n=45)$; (iii) $600-699 \mathrm{~m}^{2}$ ( $\left.n=8\right)$; (iv) $700-799 \mathrm{~m}^{2}$ ( $\left.n=8\right)$; (v) $900 \mathrm{~m}^{2}$ ( $\left.n=16\right)$; (vi) $1200-$

$4071299 \mathrm{~m}^{2}(n=8)$. RMSE was calculated for each group, the results of which are presented in Figure

408 3. The Five indices, LPI1, LPI2, LCI, ABRI and FC $_{\text {all, }}$, appear relatively stable for all six area

409 size classes. The $\mathrm{LAI}_{\mathrm{PROXY}}, \mathrm{FCI}$ and all intensity indices show a similar pattern of higher error

410 relative to the other five indices, but also larger error when plot size is smaller.

411

412

\subsection{Combining LiDAR metrics in a single model}

413 When combining all the LiDAR derived indices including the return height and intensity 414 distribution summary statistics the $\log _{10}$ transformed $A B R I$ was combined with the coefficient of 415 variation for the $\mathrm{C} 4$ crown density bin (LiDAR returns within the $3.5-4.5 \mathrm{~m}$ bin above return 416 frequency mode height) $\left(C 4_{c v}\right)$ and the skewness of vegetation return intensity (Int $\left.t_{\text {veg.skew }}\right)$. The 417 regression equation was as follows:

418

$$
L A I_{\text {pred }}=1.738+3.539 \times \log _{10}(A B R I)-0.158 \times C 4_{c v}+0.275 \times \text { Int }_{\text {veg.skew }}
$$

420 where $\mathrm{LAI}_{\text {pred }}$ is predicted LAI. The model produced an $\mathrm{R}^{2}$ value of $0.898\left(\mathrm{adj} . \mathrm{R}^{2} 0.894\right)$ with a

421 standard error of 0.345 , (see Figure 4 ). The $\mathrm{R}^{2}$ value for the three predictor model produced a 422 slightly higher $\mathrm{R}^{2}$ and lower standard error value when compared with the single predictor model 
423 including the $\log _{10}$ transformed ABRI, where $\mathrm{R}^{2}$ varied by 0.012 and standard error varied by 0.015 .

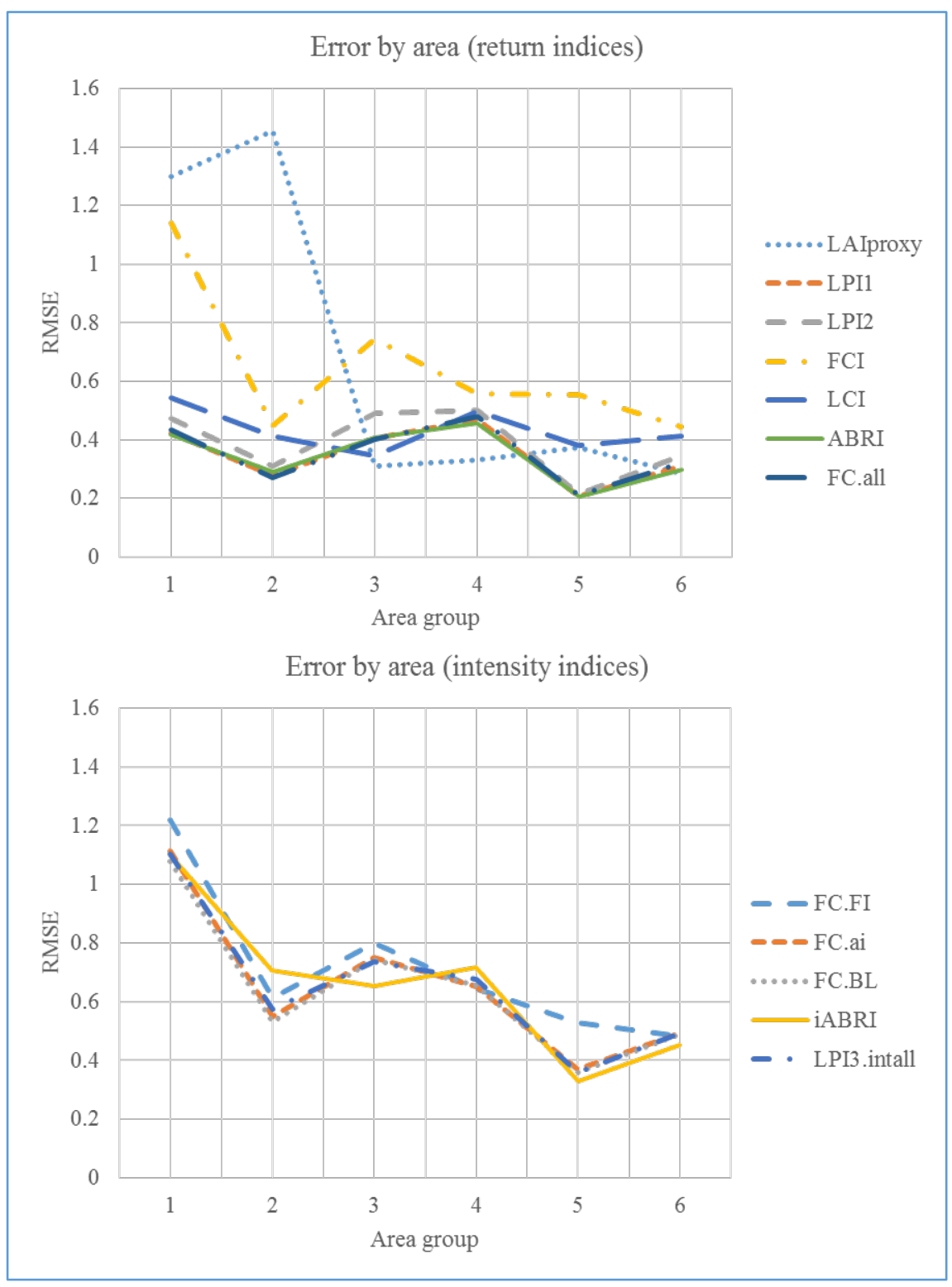

Fig.3. RMSE values from LiDAR index models calculated for groups of plot sizes (1-6). These groups were: (1) $225-399 \mathrm{~m}^{2}$; (2) $400-499 \mathrm{~m}^{2}$; (3) $600-699 \mathrm{~m}^{2}$; (4) $700-799 \mathrm{~m}^{2}$; (5) $900 \mathrm{~m}^{2}$ and (6) $1200-1299 \mathrm{~m}^{2}$. 


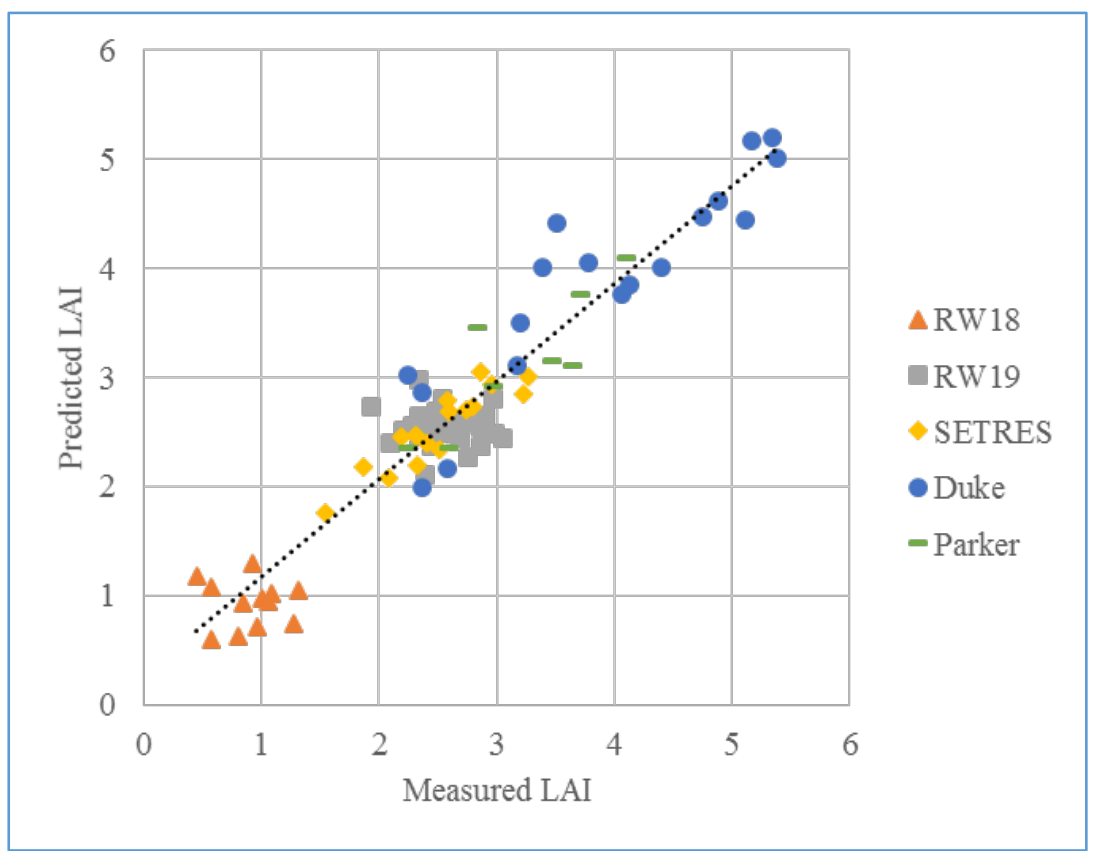

Fig.4. Graph of field measured LAI against LAI predicted from three LiDAR derived metrics (see equation 2).

\subsection{Index bivariate correlation analysis}

A matrix of the bivariate Pearson correlation relationships are summarized in Table 5. Overall, with the exception of the $L A I_{P R O X Y}$ index, all bivariate relationships are significantly correlated ( $p$ $<0.01)$. The poorest correlations existed for the $L A I_{P R O X Y}$ index, with a number of nonsignificant $(p>0.05)$ relationships between $A B R I_{\text {int }}$ and $L P I 2$, in addition to three lower significance relationships $(p<0.05)$ with FCII, LPII and ABRI. Higher correlations for the $L A I_{P R O X Y}$ were observed for those indices derived from intensity (except $A B R I_{\text {int }}$ ) and two return frequency based indices $(F C I$ and $L C I)$.

\section{Table 5}

Pearson correlation matric of LiDAR LAI related indices. Pearson coefficients (Pearson) and two-tailed significance (sig.) are listed for each bivariate correlation. ' $*$ ' indicate a significance of $<0.05$, and '**' indicate a significance of $<0.01$.

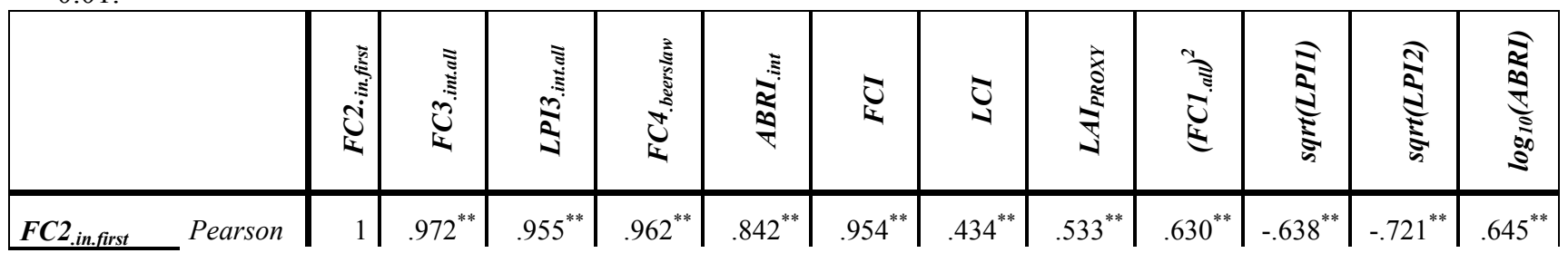




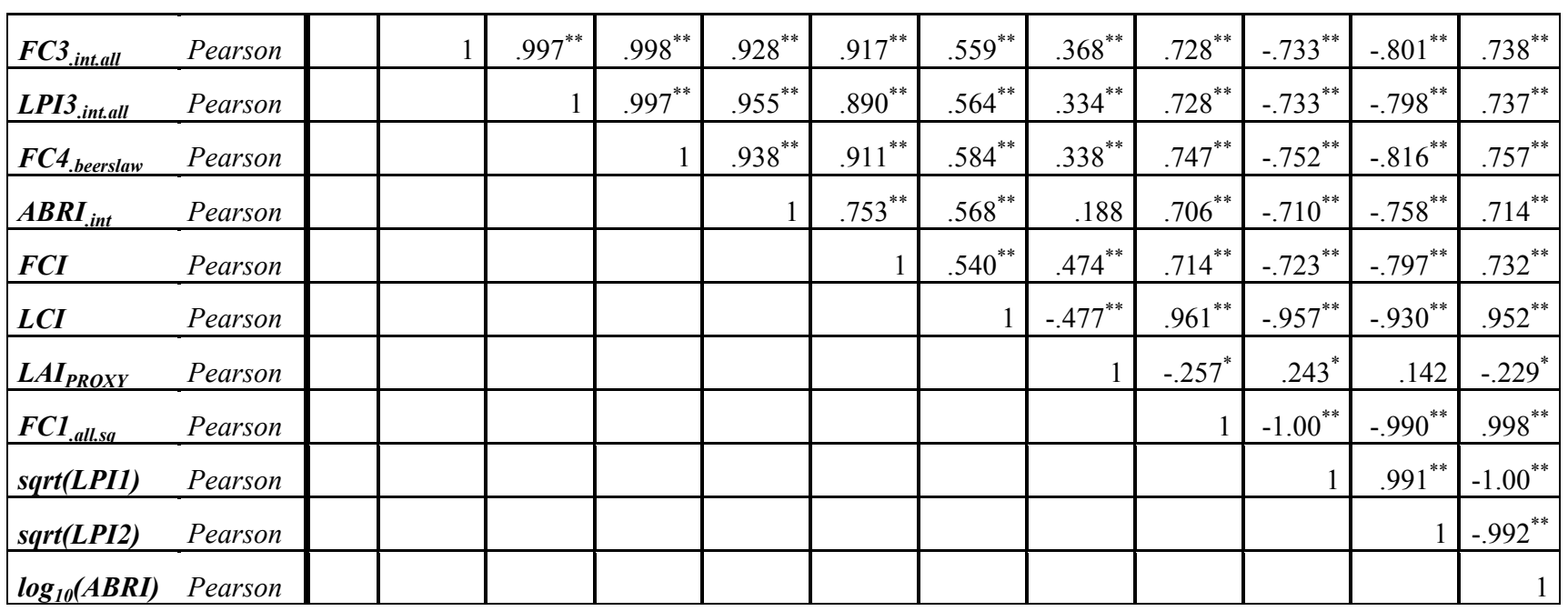

447 High correlations were observed in-between those indices derived from intensity information

448 producing high Pearson coefficient values $(r>0.84)$. Intensity indices correlated with return

449 frequency indices typically in the range of $r=0.63$ to 0.76 . Two indices, however, the $F C I$ and

450 LPI2 produced $r$ values between 0.75 and 0.95 . The $L C I$ correlated relatively poorly with the

451 intensity indices with $r$ values in the range of 0.43 to 0.58 . Those indices computed from the

452 frequency of LiDAR returns were very highly correlated with one another, and with the

453 exception of the $F C I$ and $L A I_{P R O X Y}$, Pearson correlation $(r)$ values ranged from 0.9 to 1.0.

\section{Discussion}

\subsection{Testing of predictive models}

457 The current study has tested a number of LiDAR derived indices used to predict LAI for forested 458 environments after calibration of the regression models with field data of variable plot size.

459 Overall the prediction results for the majority of the models utilizing all-return frequencies are in

460 line with the theory and results presented in previous studies (e.g. Morsdorf et al., 2006; Solberg 461 et al., 2006). A number of these LiDAR indices failed or produced a poor relationship with field 462 measured LAI however. 
464 The group of indices which produced the highest correlation with field measured LAI were based 465 upon the frequency of LiDAR returns within different portions of the forest vertical profile. The 466 highest correlations were calculated from those indices which used all returns. Those indices

467 which stratified between single, first, and last returns produced poorer results (i.e. $L A I_{P R O X Y}, F C I$ 468 and $L C I$ ). Morsdorf et al. (2006) reported an $\mathrm{R}^{2}$ for their implantation of $L A I_{P R O X Y}$ as 0.69 , which 469 is substantially different to that reported within the current project $\left(\mathrm{R}^{2} 0.07\right)$. It should be noted 470 that Morsdorf et al. (2006) developed the index for study sites containing forest species and 471 located within geographic locations not encountered within the current project, in addition to 472 using different data acquisition parameters. Korhonen et al. (2011) reported lower standard error 473 for LAI estimates derived through FCI (0.56) when compared to the results presented here 474 (0.81). Whereas the authors present a standard error for estimates using $L C I$ were 0.45 which are 475 comparable with 0.46 for the current study. With the exception of $L A I_{P R O X Y}$, which failed to 476 produce a correlation, the $F C I$ and $L C I$ exhibited distributions, when plotted, which are 477 indicative of multiple populations (see Figure 1). These groups seem to separate by study site, 478 where SETRES and RW19 (2008 acquisition) differ from similar LAI values recorded for Duke 479 and Parker (2013) datasets.

481 Non-linear relationships were identified in the remaining four return frequency based indices. 482 Barilotti et al. (2005) reported an $\mathrm{R}^{2}$ value of 0.89 when employing the LPII in linear regression 483 modeling against LAI values within a range of 3 and 6. A similar level of correlation was 484 observed in the current study $\left(\mathrm{R}^{2} 0.89\right)$, however a non-linear transformation was required within 485 the regression model. Solberg et al. (2009) reported an $\mathrm{R}^{2}$ values of 0.93 for the LPI2 over a 
486 similar range of LAI values to the current study for sites in the Østmarka forest, Norway, 487 dominated by Norway spruce. The implementation of LPI2 here returned a similar $\mathrm{R}^{2}$ value of 488 0.86. Estimates using the LPI2 within the study by Korhonen et al. (2011) report a standard error 489 of 0.38 , which are again comparable with 0.40 here. However, as described above, the 490 transformed LPI2 underestimated LAI values in the upper portions of the LAI range observed 491 (i.e. $>4$ ). The regression model for the $\log _{10}$ transformed $A B R I$ returned an $\mathrm{R}^{2}$ value of 0.89 492 which was higher than that presented in Sumnall et al. (in press) $\left(\mathrm{R}^{2}\right.$ of 0.74-0.77) which 493 employed the 2013 dataset used within the current study. The increased correlation coefficient 494 value no doubt corresponds to the increased number of samples employed within the model 495 (Strunk et al., 2012) covering a wider range of LAI values. The $F C 1_{\text {all }}$ index has been correlated 496 in previous studies with fractional cover rather than LAI, however there are parallels between the 497 two descriptive site values as they both incorporate the beer-Lambert law of light attenuation 498 (Hopkinson and Chasmer, 2009). The transformed version of the $F C 1_{\text {all }}$ index within this study 499 produced a strong linear correlation with LAI of $\mathrm{R}^{2} 0.88$, but under- or over-estimates LAI 500 values less than one or greater than four, respectively. Part of the $F C 1_{\text {all }}$ model, the 501 constant/intercept was not significant, indicating that if the index value is zero, that the predicted 502 LAI value will not significantly differ from zero.

503

504 The models utilizing the sum of intensity all produced poor results overall in terms of $\mathrm{R}^{2}(0.33$ 505 0.48) and standard error value (0.77-0.87), especially when compared to an all-return based 506 index. The models developed consistently underestimated LAI values. Whilst not a direct 507 comparison, Hopkinson and Chasmer (2009) incorporated LiDAR intensity within a number of 508 indices in order to estimate fractional cover (see Table 3) for seven study sites in Canada and 
509 including a number of different species types. The authors reported the intensity based models

510 produced the highest correlations $\left(\mathrm{R}^{2}\right.$ 0.75-0.78), when compared to indices based upon the

511 frequency of LiDAR returns $\left(\mathrm{R}^{2} 0.70-0.74\right)$.

512

513 The multi-predictor model incorporating the $\log _{10}$ transformed $A B R I$, canopy density slice and

514 skewness of intensity values did not increase the $\mathrm{R}^{2}$ value $(+0.012)$ or decrease standard error 515 value $(-0.015)$ a great deal when considering the single predictor model. There appears to be 516 little benefit to including such additional predictor metrics.

\subsection{Consideration of sensor and survey construction differences}

519 The size of the area in which to estimate LAI is also of significance. There are a number of 520 examples in the literature providing experiential evidence about the importance of plot size (e.g. 521 Zhao and Popescu, 2009; Morsdorf et al., 2006; Richardson et al., 2009). Plot size within the 522 current project was not consistent and varied from $225 \mathrm{~m}^{2}$ to $1280 \mathrm{~m}^{2}$. The standard error and plot 523 area classified RMSE appears consistent in a number of models (LPI1, LPI2, ABRI and $\left.F C 1_{\text {all }}\right)$ 524 which provided the highest correlation, for all study sites and datasets, indicating that the 525 influence of plot size was relatively low within the current context. The other indices tested, 526 however, namely the FCI and all intensity based indices appear to be sensitive to plot size (see 527 Figure 3), where RMSE is largest in small plot sizes and decreases for larger areas and is more 528 variable between groups, whilst all RMSE values are still inferior to the all-return based indices. 529 It should be considered, however, the smallest plot sizes (class 1) were from the 2013 530 acquisition, whilst the remainder were from 2008, where the trends observed may be related to 531 the two populations observed in Figure 2, and the number of plots in each area classification 
532 varied from 8 to 45 , both of which represent a possible source of bias. The results, however,

533 imply the position that all-return based indices are less limited in terms of transferability to other

534 study designs.

535

536 Setting an appropriate height threshold for the separation of ground and vegetation returns was

537 found to be optimal as the set up height of the LAI 2200 instrument in the study presented in

538 Sumnall et al. (in press). Zhao and Popescu (2009) report, however, that this may not be optimal

539 if using hemispherical photographs.

540

541 The initial field estimation of LAI is subject to a number of uncertainties (Dewey et al. 2006),

542 due to the assumptions within the algorithm applied to model LAI relating to the separation of

543 leaves from woody objects and consideration of foliage clustering. Further considerations arise

544 from field based estimates of LAI from optical instruments, which operate upon measurements

545 from an angular field of view from a point (Varhola et al., 2012), which are often recorded and

546 averaged for an area, which is in contrast to the downward vertical sampling of foliage from

547 airborne LiDAR. No information is available to define how far and what an optical sensor can

548 detect when taking measurements for the indirect estimation of LAI. For example within the

549 current study the LiCOR 2200 was used with a $90^{\circ}$ view cap, effectively removing information

550 from other directions. Such a device will also "see" further in more open canopies and a shorter

551 distance in in thicker canopies of high LAI (Zhao and Popescu et al., 2009), a situation which

552 may be further complicated in more structurally complex or heterogeneous stands. 
554 The current study has tested a number of indices cited in the related literature as having the

555 potential to predict LAI for forested environments once calibrated. A number of trends are

556 evident from the analysis presented here, where the models which were most highly correlated

557 with field recorded LAI were calculated from the sum of all LiDAR returns. Those models which

558 produced low correlations or exhibited patterns where there were distinct groups when viewed

559 graphically were constructed using combinations of first, last or single returns, or used the sum

560 of return intensity. In reference to Figure 1, the FCI exhibits at least two non-linear populations

561 in addition to a cluster of lower values corresponding to those records from RW18. The graphical

562 output for the LCI appears to show two populations corresponding to the datasets from 2008 for

563 lower values of LAI and 2013 for higher values. The index LPI2 utilizes single, first and last

564 returns within its calculation, but does not exhibit patterns within the predicted values, it does

565 however underestimate higher values of LAI, i.e. those encountered in the sites recorded in 2013.

566 This implies that there is a disparity between the proportions of first, last or single returns

567 recorded by the two different sensors in the separate 2008 and 2013 acquisitions, therefore,

568 methods based on such approaches cannot be transferred to other sites or acquisition parameters.

569

570 These two distinct sensors will have a different sensitivity to the detection of multiple features

571 per pulse (Næsset, 2009; Hopkinson, 2006), thus the proportions of first-of-many, single and last

572 returns will differ when comparing systems capable of detecting differing types of returns. The

573 Optech ALTM 3100 system could record up to four returns per pulse, whereas the Riegl VQ-480

574 could record up to six. The sensor pulse frequency also differs between the two acquisitions

$575(70 \mathrm{kHz}$ and $150 \mathrm{kHz})$. Hopkinson and Chasmer (2009) investigated the differences in sampling

576 density and reported that models constructed from return frequency ratios (e.g. $F C 1_{\text {all }}$ ) could 
577 produce comparatively higher estimates of fractional cover at lower frequencies. Thus, a lower

578 frequency of sampling would result in a systematically higher number of returns recorded within

579 the upper forest canopy than for a higher sampling frequency. It should be noted that the 580 investigation in Hopkinson and Chasmer (2009) was applied to a single study site, the 581 observations may not be applicable across all other potential sites and acquisitions. There were 582 no appreciable differences in estimates between the two datasets which utilized all the LiDAR 583 returns within this current project when LAI ranges overlapped (e.g. $A B R I$ and $L P I 1$ ). Indices 584 using first returns, such as the $F C I$, expresses similarities to the phenomena described above, 585 especially for the SETRES and RW19 sites. These issues appear symptomatic of locational or 586 data acquisition specific differences which may pose problems to the transferability of LiDAR 587 based LAI models, in particular those employing the ratios of different return types. Future 588 studies should test those models identified within the current study for their validity in different 589 forest types and geographical locations.

Hopkinson and Chasmer (2009) also stated that indices calculated from intensity were not 592 affected by the frequency of the sampling or pulse power. Within the current project, however, 593 indices calculated from intensity performed poorly and when plotted revealed the presence of 594 two populations with linear or non-linear appearance for the SETRES and RW19 sites (from 595 2008) and the Duke and Parker sites (from 2013) over a similar range of LAI values. It should 596 also be noted that the two systems used a different wavelength for the laser pulse within the 597 current study, where differences in laser reflection properties resulting in 'brighter' returns at 598 different wavelengths could account for some differences (Li et al., 2013). The storage of the 599 recorded intensity values also differed between the 2008 and 2013 datasets, resulting in the latter 
600 having a lower resolution dataset. The usage of LiDAR intensity remains a contested issue due to

601 the proprietary methods that commercial sensors use to report return intensity which can change

602 in flight, making it impossible to directly compare two returns, such as the reflectivity of the

603 target and the amount of the pulse interacting with the target (Lim et al., 2003a). Unless some

604 technique of calibrating intensity values is applied to the data acquired from different

605 acquisitions, the transferability of such models does not appear to be possible.

606

\section{4.3. Implications and considerations}

608 The LiDAR sensor emits numerous near-infrared pulses, where some will be reflected from the 609 canopy and some will reach the ground. Fundamentally, the ratio of how many returns are from 610 the ground and how many are returned from on or within the canopy has shown to be directly 611 related to plant area and therefore leaf area.

613 Each of the LiDAR indices used within the current project share similarities in term of their 614 calculation, where the number or sum of intensity values of ground, canopy and all returns are 615 ratioed against one another. The similarity in terms of information content is further exemplified 616 when considering the bivariate correlation matrix presented in Table 5, where significant $(p<$ 617 0.01) relationships existed for all the indices, with the exception of $L A I_{P R O X Y}$. High correlations 618 were found between intensity based indices and the $F C I$, which was calculated from the ratio of 619 first returns, which is unsurprising given the similarity in the pattern of values (see fig. 1 and 2). 620 High correlation values existed for many of the bivariate relationships, which was especially 621 evident between those indices using return frequency. Those highest correlations were recorded 622 for $A B R I, F C 1_{\text {all }}, L P I 1$, and even $L C I$ when considering the issues mentioned previously. Each of 
623 these indices also provided the highest correlation with field LAI. Where each of these indices

624 ratio different components (ground, canopy and all returns) and work for all practical purposes, 625 and thus equate to the same thing.

626

627 The results of the current study illustrate the differences in LiDAR sensors and the issues relating 628 to the methods each system uses to record data for analysis. The differences encountered 629 between the proportions of return types (e.g. first, last, etc.) and intensity values imply that 630 methods using this data are critically limited in terms of their transferability to other LiDAR 631 acquisitions. The use of indices calculated from all-returns, however, appear compatible with 632 different LIDAR sensor datasets, and therefore are potentially transferable, at least for Loblolly 633 pine forest.

634

635 Parallels can be drawn to the model development of optical-spectral indices which are often used 636 to estimate LAI, where many indices are calculated from a ratio or difference between different 637 portions of the reflected spectrum of electromagnetic radiation (Bannari et al., 1995), for 638 example the red edge and the chlorophyll trough, with one such example being the Normalized 639 Difference Vegetation Index (NDVI). For homogenous closed stand conditions, it makes little 640 difference which vegetation index used to estimate LAI because they are all fundamentally 641 linked to the same thing (Broge and Leblanc, 2001). Thus, the argument can be made that a 642 similar level of maturity has been achieved with respect to the estimation of LAI using the 643 LiDAR return frequency based indices (all returns) as with spectral vegetation indices, such as 644 the NDVI and its variants. 
646 Overall, techniques such as the use of spectral indices can approximate LAI for canopies with 647 LAI in the range of 3-5 (Chen and Chilar, 1996, Turner et al., 1999). Issues arise for values 648 above this LAI threshold, as many indices saturate causing LAI estimates for high biomass to be 649 incorrectly estimated. The spatial resolution of satellite imagery, especially, can lead to the 650 mixture of surface cover types into a single value, for example thinned and open plot understory 651 and ground reflectance can adversely affect estimates of LAI. While the saturation of LiDAR 652 derived indices is possible, the results presented in the current study suggest LiDAR estimates of 653 LAI are not as limited by saturation effects and can estimate LAI values over a range between 654 zero to in excess of five, at relatively small spatial resolutions, which are also less sensitive to 655 understory presence and are less subject to the increases error associated with thinned and open 656 areas within a forest context. In addition, the link between field LAI measurement height and the 657 threshold of what defined 'ground' and 'canopy' within LiDAR returns, as suggested in Sumnall 658 et al. (in press), implies that estimates of the vertical distribution of LAI vertically through the 659 canopy is possible.

660

661 In densely vegetated forest environments there is the possibility that no LiDAR laser pulses will 662 penetrate and return from the depth required for the computation of the index, which would 663 result in inaccurately predicting the LAI value. A parallel can be drawn from vegetation indices 664 developed for multispectral data, such as the NDVI which saturate at higher LAI values (Wang 665 et al., 2005). The inclusion of the scanning angle of each laser pulse could be incorporated in the 666 model construction, as at larger scanning angles the laser pulse may penetrate through gaps 667 which would not be possible at near-nadir angles (Richardson et al., 2009), although additional 668 concerns relating to scan length, pulse energy and light attenuation would need to be addressed. 
669 The likelihood of increasing the number of returns from the lower portions of the LiDAR vertical 670 profile potentially increases with larger plot size. Advances in small-footprint LiDAR

671 technologies, such as full-waveform, could potentially provide a greater number of returns per

672 pulse (Chauve et al., 2007) and reduce an issue prevalent in discrete return LiDAR, where there 673 is a 'blind spot' following each detected return (up to 1.2-5m), during which nothing can be 674 detected (Reitberger et al., 2008).

675

676 The current study included a range of Loblolly pine stands with differing management types 677 applied, some of which included understory control. A number of these stands, in particular 678 Duke or Parker Tract, included a number of multiple vertical layers, where both coniferous and 679 deciduous species were present in the shrub, understory and mid-story layers beneath the 680 dominant canopy. The presence and absence of vegetation within these layers will influence the 681 total LAI of a given area, and will alter throughout the year in temperate regions. Given LiDARs 682 ability to penetrate the canopy and estimate the presence of sub-canopy features (e.g. Hill and 683 Broughton, 2009), future work could attempt to estimate the presence of these layers and the 684 potential influence upon area-total LAI they have.

685

\section{5. Conclusions}

687 The application of airborne LiDAR for estimating LAI can provide a number of benefits in 688 comparison to the analysis of optical multispectral data in terms of accuracy and scale, 689 particularly in areas of medium to high biomass and were forest canopy cover is not uniform 690 over large areas. The current study demonstrates the usefulness of a number of LiDAR derived 691 indices calculated from the ratio of returns from different portions of the vertical return 
692 information provided, for predicting LAI from multiple datasets from Loblolly pine dominated

693 forest of homogeneous canopy types. The investigated predictors included a variety laser-

694 penetration indices using either frequency of return or the sum of return intensity over a variety

695 of stand ages, forest management conditions and geographical locations.

696

697 The non-linear transformed $\log _{10}$ ABRI and square root transformed LPI1 have demonstrated the 698 strongest correlations with field estimates of LAI, by LAI 2000/LAI 2200. The addition of other

699 LiDAR derived return frequency or intensity distribution did not improve prediction accuracy to 700 any great degree. These indices are capable of predicting LAI across two disparate sensor or data 701 acquisition configurations, and offer the potential of a transferable model, at least for managed 702 Loblolly pine sites. Those indices derived from single, first-of-many and last returns or the sum 703 of return intensities consistently produced inferior correlations and exhibited a number of 704 differences in terms of value distribution which indicates separate populations corresponding to 705 the data from the two separate LiDAR acquisitions, in addition to concerns over sensitivity to 706 plot size. This implies that indices developed using such data from disparate LiDAR sensor or 707 data acquisition configurations are not transferable. Alternatively, it suggests that such indices 708 should be calibrated independently for each change in survey configuration.

710 Many of the LiDAR derived indices were highly correlated with one another. Those indices 711 derived from the frequency of all LiDAR returns in particular (e.g. $L P I 1$ and $A B R I$ ), all used 712 ratios of returns from different vertical parts of the canopy, but ultimately produced very similar 713 results in terms of predicted LAI. This indicates a similar level of development to multispectral 714 indices for the estimation of LAI. 
716 The results of the current study offer the potential to estimate LAI robustly from airborne LiDAR

717 data consistently when employing multiple sensor or data acquisition configurations for managed

718 Loblolly pine stands at various field-plot scales. This may hold the potential for reducing the

719 need to calibrate LiDAR data against field measured LAI in the future. There is a great deal of 720 disparity within the current literature regarding the estimation of LAI from LiDAR however, 721 with the metrics used in many studies which are site specific (Zhao and Popescu, 2009). At this 722 stage it may be premature to state that there is one 'ideal' model for estimating LAI, thus future 723 work should place an emphasis on assessing the transferability of published methods to new 724 geographic contexts, sensor types and survey characteristics. In addition given LiDARs ability to 725 penetrate through the dominant canopy and identify sub-canopy features it may be possible to 726 estimate how LAI changes throughout the vertical profile, and what the data requirements of this 727 might be.

\section{6. Acknowledgements}

730 This research was possible thanks to the support from the Forest Productivity Cooperative, the 731 help in field data collection provided by Beth Stein and the assistance Alica Peduzzi, who 732 provided the field data for validation of the 2008 LiDAR acquisition assessed in the project. We 733 gratefully acknowledge the support and LiDAR data supplied by NASA, in addition to the 734 support of the staff members of the Duke Forest teaching and research laboratory, the Northern 735 Research Station Strategic Foresight Group of the North Carolina Forest service and the 736 landowner Weyerhaeuser. Funding for this work was provided in part by the Virginia 
Food and Agriculture, U.S. Department of Agriculture.

\section{References}

Anderson, J. E., Plourde, L. C., Martin, M. E., Braswell, B. H., Smith, M. L., Dubayah, R. O., Hofton, M. A., and Blair, J. B., 2008. Integrating waveform lidar with hyperspectral imagery for inventory of a northern temperate forest. Remote Sensing of Environment, 112 (4), 1856-1870.

Armston, J. (2014) RSC Las Tools - version 1.9.3 [Computer program] Available from: $<$ https://code.google.com/p/rsclastools/>

Bannaria, A., Morina, D., Bonna, F. and Hueteb, A.R. 1995. A review of vegetation indices. Remote Sensing Reviews. Vol. 13 (1-2), pp. 95-120.

Barilotti, A., Turco, S., Napolitano, R., Bressan, E., 2005. La tecnologia LiDAR per lo studio della biomassa negli ecosistemi forestali. In: 15th Meeting of the Italian Society of Ecology, Torino, Italy.

Bioucas-Dias, J, M., Plaza, A., Dobigeon, N., 2012. Hyperspectral Unmixing Overview: Geometrical, Statistical, and Sparse Regression-Based Approaches. IEEE Journal of Selected Topics in Applied Earth Observations and Remote Sensing. Vol. 5 (2), pp. 354-379.

Bowerman, B.L. and O'Connell, R.T. 1990. Linear statistical models: an applied approach (2 $2^{\text {nd }}$ ed.). Belmont, CA: Duxbury.

N.H Broge, N., H. and Leblanc, A. 2001. Comparing prediction power and stability of broadband and hyperspectral vegetation indices for estimation of green leaf area index and canopy chlorophyll density. Remote Sensing of Environment. Vol. 76 (2), pp. 156-172.

Chen, J.M.; Chen, X.Y.; Ju, W.M.; Geng, X.Y. 2005 Distributed hydrological model for mapping evapotranspiration using remote sensing inputs. J. Hydrol. 305, 15-39.

Chen, J. and Chilar, J. 1996Retrieving leaf area index of boreal forests using Landsat TM images. Remote sensing of environment, 55, 153-162.

Cleugh, H.A.; Leuning, R.; Mu, Q.; Running, S.W. 2007Regional evaporation estimates from fluxtower and MODIS satellite data. Remote Sensing of Environment, 106, 285-304.

Cook, B. D., L. W. Corp, R. F. Nelson, E. M. Middleton, D. C. Morton, J. T. McCorkel, J. G. Masek, K. J. Ranson, V. Ly, and P. M. Montesano. 2013. NASA Goddard's Lidar, Hyperspectral and Thermal (G-LiHT) airborne imager. Remote Sensing Vol. 5, pp. 4045-4066.

Dewey, J. C., Roberts, S. D. and Hartley, I. 2006. A comparison of tools for remotely estimating Leaf area index in Loblolly pine plantations. In: Connor, K. F. (Ed.). Proceedings of the $13^{\text {th }}$ biennial southern silvicultural research conference Gen. Tech. Rep. SRS92 (pp. 77-75) Ashville, NC: US Dept. of Agriculture, Forest service, southern research station, pp. 640. 
Duchemin, B.; Hadriab, R.; Errakib, S.; Bouleta, G.; Maisongrandea, P.; Chehbounia, A.;Escadafala, R.; Ezzaharb, J.; Hoedjesa, J.C.B.; Kharroud, M.H.; Khabbab, S.; Mougenota, B.;Oliosoe, A.; Rodriguezf, J.C.; Simonneauxa, V. 2006 Monitoring wheat phenology and irrigation in: Central Morocco: On the use of relationships between evapotranspiration, crops coefficients, leafarea index and remotely-sensed vegetation indices. Agric. Water Manage, 79, 1-27.

Erikson, H. M., Eklundh, L., and Kuusk, T. 2006. Impact of understory vegetation on forest canopy reflectance and remotely sensed LAI estimates. Remote Sensing of Environment. Vol. 103, pp. 408418.

Evans, J. S., Hudak, A. T., Faux, R., and Smith, A. M. S., 2009. Discrete return lidar in natural resources: Recommendations for project planning, data processing, and deliverables. Remote Sensing, Vol. 1 (4), 776-794.

Falkowski, M. J., Evans, J. S., Martinuzzi, S., Gessler, P. E., and Hudak, A. T., 2009. Characterizing forest succession with lidar data: An evaluation for the inland northwest, USA. Remote Sensing of Environment, 113 (5), 946-956.

Field, A. 2013. Discovering statistics using SPSS (fourth editions). SAGE Publications Ltd; California, USA.

Hill, R. A., and Broughton, R. K., 2009. Mapping the understorey of deciduous woodland from leaf-on and leaf-off airborne lidar data: A case study in lowland Britain. ISPRS Journal of Photogrammetry and Remote Sensing, Vol. 64 (2), 223-233.

Hopkinson, C. 2006. The Influence of LiDAR Acquisition Settings on Canopy Penetration and Laser Pulse Return Characteristics. In proceeding of: Geoscience and Remote Sensing Symposium.

Hopkinson, C. and Chasmer, L., 2009. Testing LiDAR models of fractional cover across multiple forest ecozones. Remote Sensing of Environment. Vol. 113, pp. 275-288.

Hudak, A. T., Crookston, N. L., Evans, J. S., Hall, D. E., and Falkowski, M. J., 2008. Nearest neighbor imputation of species-level, plot-scale forest structure attributes from lidar data. Remote Sensing of Environment, 112 (5), 2232-2245.

Kaartinen, H., Hyyppa, J., Yu, X. W., Vastaranta, M., Hyyppa, H., Kukko, A., Holopainen, M., Heipke, C., Hirschmugl, M., Morsdorf, F., Naesset, E., Pitkanen, J., Popescu, S., Solberg, S., Wolf, B. M., and $\mathrm{Wu}$, J. C., 2012. An international comparison of individual tree detection and extraction using airborne laser scanning. Remote Sensing, Vol. 4 (4), 950-974.

Korhonen, L., Korpela, I., Heiskanen, J. and Maltamo, M. 2011. Airborne discrete-return LiDAR data in the estimation of vertical canopy cover, angular canopy closure and leaf area index. Remote Sensing of Environment. Vol. 115, pp. 1065-1080.

Lefsky, M. A., Cohen, W. B., Parker, G. G., and Harding, D. J., 2002. Lidar remote sensing for ecosystem studies. Bioscience, Vol. 52 (1), 19-30.

Leuning, R.; Cleugh, H.A.; Zegelin, S.J.; Hughes, D. 2005Carbon and water fluxes over a temperate Eucalyptus forest and a tropical wet/dry savanna in Australia: measurements and comparison with MODIS remote sensing estimates. Agric. For. Meteorol, 129, 151-173. 
Li, Z., Douglas, E., Strahler, A., Schaaf, C., Yang, X.,Y., Wang, Z.,S., Yao, T., Zhao, F., Saenz, E., J., Paynter, I., Woodcock, C., E., Chakrabarti, S., Cook, T., Martel, J., Howe, G., Jupp, D., L., B., Culvenor, D.,S., Newnham, G.,J., Lovell, J., L., 2013. Separating leaves from trunks and branches with duel-wavelength terrestrial LiDAR scanning. In: IEEE International Symposium on Geoscience and Remote Sensing IGARSS. Melbourne, Australlia, pp. 3383-3386.

Lim, K., Treitz, P., Baldwin, K., Morrison, I., and Green, J., 2003a. Lidar remote sensing of biophysical properties of tolerant northern hardwood forests. Canadian Journal of Remote Sensing, Vol. 29 (5), 658-678.

Lim, K., Treitz, P., Wulder, M., St-Onge, B., and Flood, M., 2003b. Lidar remote sensing of forest structure. Progress in Physical Geography, Vol. 27 (1), 88-106.

Maltamo, M., Packalen, P., Yu, X., Eerikainen, K., Hyyppa, J., and Pitkanen, J., 2005. Identifying and quantifying structural characteristics of heterogeneous boreal forests using laser scanner data. Forest Ecology and Management, Vol. 216 (1-3), 41-50.

Morsdorf, F., Kötz, B., Meier, E., Itten, K.I. and Allgöwer, B. 2006. Estimation of LAI and fractional cover from small footprint airborne laser scanning data based in gap fraction. Remote sensing of environment, Vol. 104, 50-61.

Næsset, E., 2002. Predicting forest stand characteristics with airborne scanning laser using a practical two-stage procedure and field data. Remote Sensing of Environment, Vol. 80 (1), 88-99.

Naesset, E. 2009. Effects of different sensors, flying altitudes, and pulse repetition frequencies on forest canopy metrics and biophysical stand properties derived from small-footprint airborne laser data. Remote sensing of environment, Vol. 113, pp. 148-159.

Peduzzi, A., Wynne, R.,H,. Thomas, V.,A., Nelson, R.,F., Reis, J.,J., Sanford, M., 2012a. Combined Use of Airborne Lidar and DBInSAR Data to Estimate LAI in Temperate Mixed Forests. Remote Sensing. Vol. 4(6), pp. 1758-1780.

Peduzzi, A., Wynne, R., H., Fox, T., R., Nelson, R. and Thomas, V., A., 2012b. Estimating leaf area index in intensively managed pine plantations using airborne laser scanner data. Forest Ecology and Management. Vol. 270, pp. 54-65.

Reitberger, J., Krzystek, P., and Stilla, U., 2008. Analysis of full waveform lidar data for the classification of deciduous and coniferous trees. International Journal of Remote Sensing, Vol. 29 (5), 1407-1431.

Richardson, J., Moskal, M., Kim, S., 2009. Modeling approaches to estimate effective leaf area index from aerial discrete return LiDAR. Agricultural and Forest Meteorology. Vol. 149, pp. 1152-1160.

Solberg, S., Brunner, A., Hanssen, K., H., Lange, H., Næsset, E., Rautiainen, M. and Stenberg, P., 2009. Mapping LAI in Norway spruce forest using airborne laser scanning. Remote Sensing of Environment. Vol. 113, pp. 2317-2327.

Stenberg, P. 1996. Correcting LAI-2000 estimates for the clumping of needles in shoots of conifers. Agricultural and Forest Meteorology. Vol. 79, 1-8. 
Strunk, J., Temesgen, H., Andersen, H. E., Flewelling, J. P., and Madsen, L., 2012. Effects of lidar pulse density and sample size on a model-assisted approach to estimate forest inventory variables. Canadian Journal of Remote Sensing, Vol. 38 (5), pp. 644-654.

Sumnall, M., J., Fox, T., R., Wynne, R., H., Blinn, C., and Thomas, V., A., in press. Estimating Leaf Area Index at multiple heights within the understorey component of Loblolly pine forests from airborne discrete return LiDAR.. International Journal of Remote Sensing.

Turner, D. P., Cohen, W.B., Kennedy, R. E., Fassnacht, K. S. and Briggs, J. M. 1999. Relationship between leaf area index and Landsat spectral vegetation indices across three temperate zone sites. Remote sensing of environment, 70, 52-68.

Varhola, A., Frazier, G.W. Teti, P., and Coops, N.C. 2012. Estimation of forest structure metrics relevant to hydrological modelling using coordinate transformation of airborne laser scanning data. Hydrology and Earth System Sciences: 16: 3749-4376.

Wang, Q., Adiku, S., Tenhunen, J. and Granier, A. 2005. On the relationship of NDVI with leaf area index in a deciduous forest site. Remote sensing of Environment, 94(2), 244-255.

Zhang, K., Chen, S., Whitman, D., Shyu, M., Yan, J. and Zhang, C., 2003. A Progressive Morphological Filter for Removing Nonground Measurements from Airborne Lidar Data. IEEE Transactions on Geoscience \& Remote Sensing, Vol. 41(4), pp. 872-882.

Zhao, K. and Popescu, S., 2009. LiDAR-based mapping of leaf area index and its use for validating GLOBCARBON satellite LAI product in a temperate forest of the southern USA. Remote Sensing of Environment. Vol. 113, pp. 1628-1645. 